\title{
Role of CA125 in the Diagnosis of Acute Appendicitis
}

\author{
Barış Sevinç ${ }^{1}$ Ersin Turan², Hüseyin Kurku³, Ömer Karahan ${ }^{1}$ \\ 'Department of General Surgery, Uşak University School of Medicine, Uşak, Turkey \\ ${ }^{2}$ Clinic of General Surgery, Beyhekim State Hospital, Konya, Turkey \\ ${ }^{3} \mathrm{Clinic}$ of Biochemistry, Konya Training and Research Hospital, Konya, Turkey
}

\begin{abstract}
Aim: Acute appendicitis (AA) is the most common surgical emergency in the world, and its diagnosis is mainly dependent on clinical findings. Recently, secretion of CA125 from peritoneal cells due to inflammatory stimulus has been shown. The aim of this study was to evaluate the relation between CA25 levels and AA.
\end{abstract}

Materials and Methods: In this prospective trial, CA125 levels were measured. Group 1 consisted histopathologically approved AA cases. Group 2 consisted healthy individuals.

Results: Seventy-four cases (37 AA and 37 healthy individuals) were included in the study. In the AA group, the mean CA125 level was $9.8 \pm 9.3 \mathrm{U} / \mathrm{mL}$, and in the control group, it was $4.6 \pm 1.5 \mathrm{U} / \mathrm{mL}$. In Pearson correlation analysis, the CA125 level had a positive correlation with $A A(r=0.371, p=0.001)$.

Conclusion: Recent studies demonstrate that CA125 can help distinguish patients with or without AA. CA125 levels can be used as a marker of AA in cases with clinical doubt.

Keywords: Acute appendicitis, diagnosis, CA-125

\section{Introduction}

Acute appendicitis (AA) is the most common surgical emergency in the world (1). Diagnosis of AA mainly depends on clinical findings. Laboratory markers and radiological studies play only a supportive role. Although developments in clinical, laboratory, and radiologic tools, negative appendectomy rate is still 15\% (2). There are several markers are still being researched for correlation of definitive diagnosis of AA. Mainly leukocyte number and C-reactive protein are used for laboratory markers. However, they only show inflammation and are not specific to AA (3, 4). There is still no specific laboratory or clinical marker of AA.

Recently, a number researches are made for improving the medical treatment of AA (5-8). In such an era of medical treatment, definitive diagnosis plays a very important role. Recent data support evidence of successful medical treatment of uncomplicated AA cases. However, the main problem in these reports is that the exact number of negative appendicitis cases in medical treatment arm is not known.

CA125 is a glycoprotein secreted from mesothelial cells. It is mainly used in the diagnosis and post-op follow-up of gynecological tumors. In males, the main source of CA125 is liver cirrhosis (9). Recently, secretion of CA125 from peritoneal cells due to inflammatory stimulus has been shown. Although there are a few of studies showing the relation between CA125 and $A A$, the evidence is not strong enough for the routine use of CA125 in cases suspected of AA.

The aim of this study was to evaluate the relation between CA125 levels and histopathologically approved AA.

\section{Materials and Methods}

For this prospective controlled study, ethical approval was obtained from ethics committee of the Selçuk University Medical School (Date: December 24, 2013; number: 2013/378). The study was conducted at a tertiary training and research hospital between February 2014 and February 2015.

For the power analysis, the CA125 levels reported by Berger et al. (10) were considered. According to Berger et al. (10), the mean CA125 levels of patients with and without AA were $9.9 \pm 4.7$ and $7.8 \pm 3.2 \mathrm{U} / \mathrm{mL}$, respectively. In the power analysis, we used those levels. With a power of $80 \%$ and a beta error of 0.05 , we had to include 37 cases in each group.

To exclude the effect of ovarian disorders and fluctuations during menstrual cycles on CA125 levels, only male cases were included in this study. 
Male patients admitted to the surgery department with diagnosis of AA were considered for the study. After informed consent, serum samples from all the cases with clinical diagnoses of AA were obtained and stored. Only the cases with histopathologically approved AA were included in the study. Cases operated for clinical diagnosis of $A A$, but not histopathologically proven $A A$ were not included in the study. CA125 levels in cases with definitive diagnosis of $A A$ were measured.

For the control group, serum samples from healthy volunteers were obtained, and CA125 levels were measured.

\section{Statistical analysis}

For statistical analysis, IBM Statistical Package for the Social Sciences (IBM SPSS Statistics; Armonk, NY, USA) 20 package software was used. Data was presented as mean \pm standard deviation (SD). In comparison of the groups, the Student t-test was used. For determination of correlation, Pearson correlation analysis was used and correlation coefficients are presented. CA125 values in predicting AA were analyzed using receiver operating characteristics (ROC) curve analysis. When a significant cutoff value was observed, the sensitivity and specificity were presented. Statistical significance level ( $p$-value) was accepted as 0.05 .

\section{Results}

Seventy-four male subjects were included in the study. There were $37 \mathrm{AA}$ cases in the study group and 37 healthy volunteers in the control group. The mean age of the patients was $27.7 \pm 8.4$ years. The groups were similar in terms of mean age [29.6 \pm 11.03 and $25.9 \pm 4$ years, respectively $(p=0.61)]$. Demographic data, mean hemoglobin and leukocyte counts, and CA125 levels are presented in Table 1. The distribution of the pathological diagnosis of the operated cases are presented in Table 2 .

The mean CA125 level was $9.8 \pm 9.3 \mathrm{U} / \mathrm{mL}$ in the AA group and $4.6 \pm 1.5 \mathrm{U} / \mathrm{mL}$ in the control group (Figure 1). The difference between the groups was statistically significant $(p=0.001)$. In Pearson correlation analysis, the CA125 level had a positive correlation with AA $(r=0.371, p=0.001)$.

According to the ROC curve, the optimal CA125 value for AA was found to be $5.22 \mathrm{U} / \mathrm{mL}$ with a sensitivity of $81 \%$ and specificity of $65 \%$ (AUC $=0.795, p<0.001$ ) (Figure 2).

\section{Discussion}

The present study evaluated the relation between CA125 levels and AA. The results demonstrate a significant increase in CA125 levels in cases with AA and a significant decrease in CA125 levels after appendectomy.

Acute appendicitis is the most common surgical emergency. If untreated, it may cause complications and mortality. Complicated AA comprises $18-34 \%$ of cases $(11,12)$. Main complications are perforation and abscess formation. A delay in diagnosis can result in perforation rates as high as $80 \%(13,14)$. Perforation may lead to peritonitis and even sepsis and death. Diagnosis of AA mainly depends on clinical findings. Laboratory and imaging studies can be used as accessory modalities. Ultrasonography and computed tomography are commonly used imaging studies. The sensitivity and specificity of ultrasonography are $99.1 \%$ and $91.7 \%$, respectively. For computed tomography, sensitivity is reported as $96.4 \%$ and specificity is reported as $95.4 \%(15)$. There are several laboratory markers evaluated for the diagnosis of AA. C-reactive protein and leukocyte counts are
Table 1. Demographic data, mean hemoglobin, leukocyte count, and CA 125 levels of the cases and controls

\begin{tabular}{|l|c|c|c|}
\hline & Case & Control & p* $^{*}$ \\
\hline Age $($ mean \pm SD) & $29.6 \pm 11$ & $25.9 \pm 4$ & 0.061 \\
\hline Hemoglobin level $(\mathrm{g} / \mathrm{dL})($ mean \pm SD) & $14.2 \pm 1.1$ & $14.3 \pm 0.9$ & 0.869 \\
\hline Leukocyte count (mean \pm SD) & $11.9 \pm 1.04$ & $7.4 \pm 2.1$ & 0.001 \\
\hline CA-125 level (mean \pm SD) & $9.8 \pm 9.3$ & $4.6 \pm 1.5$ & 0.001 \\
\hline *Student t-test. SD: standard deviation & & \\
\hline
\end{tabular}

Table 2. Distribution of pathological diagnosis of the cases

\begin{tabular}{|l|c|c|}
\hline & n & \% \\
\hline Simple appendicitis & 22 & 59.5 \\
\hline Gangrenous appendicitis & 10 & 27 \\
\hline Perforated appendicitis & 5 & 13.5 \\
\hline
\end{tabular}

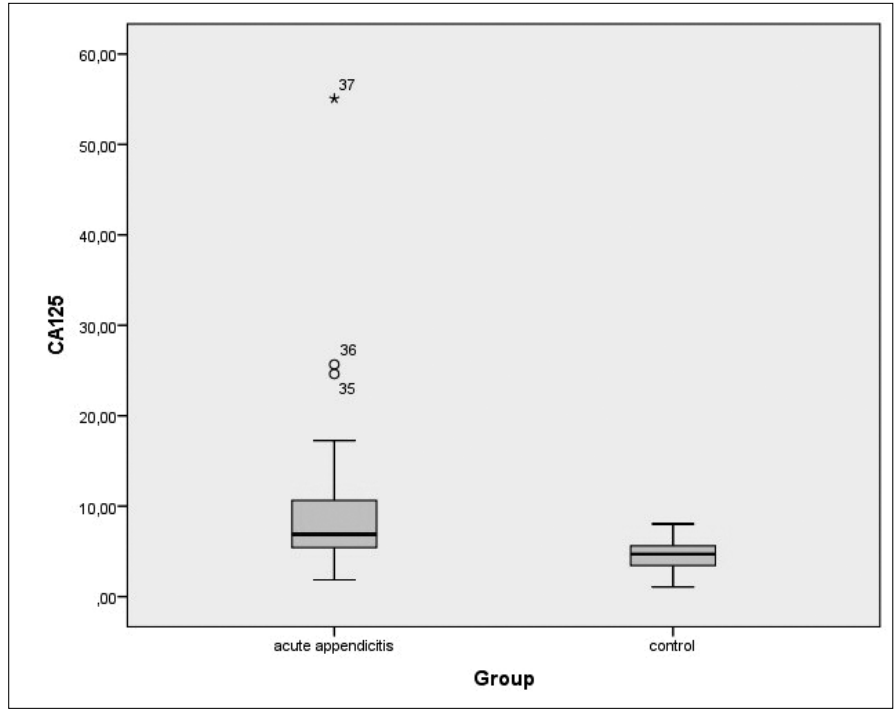

Figure 1. CA125 values according to group

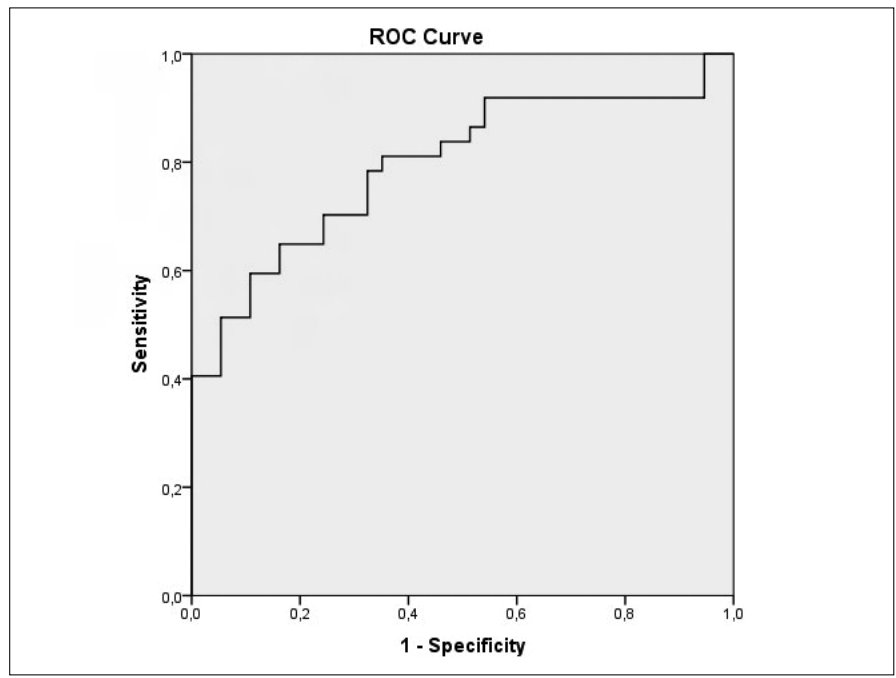

Figure 2. ROC curve for $C A 125$ value for diagnosis of acute appendicitis 
routinely used at emergency departments. Other inflammatory mediators like interleukins and procalcitonin are evaluated for diagnosis of AA $(3,4)$. However, in a meta-analysis they found no useful effect of several mediators on $A A$ diagnosis (3).

The gold standard treatment for AA is appendectomy; however, recent literature shows that uncomplicated cases can be treated medically. There are several reports on the medical treatment of AA. A recent meta-analysis reported that medical treatment can be chosen in uncomplicated cases (16). In studies evaluating the antibiotic treatment of $A A$, the main debate is that the negative appendicitis rate is not known. Traditionally, the negative appendectomy rate is about $15 \%$, which can decrease to $10 \%$ with the use of computed tomography (17). However, in trials with only antibiotic treatment, determination of the exact negative case rate is impossible. Therefore, there is a need for certain diagnosis of AA. The Alvarado score is a widely-used scoring system for the diagnosis of AA (18). However, the sensitivity of this scoring system is low in cases with low scores. In a study, the low modified Alvarado score was less sensitive compared with unstructured clinical judgment (19).

CA125 is glycoprotein mainly secreted from mesothelial cells. It is commonly used as a tumor marker for gynecological cancer. However, it secretion from peritoneal epithelium in case of inflammation is demonstrated by in vitro studies (9). According to Basaran (20), the main debate is thatCA125 secretion begins six hours after the onset of inflammation. In AA, both visceral and parietal peritoneum are affected. Therefore, theoretically, at the time of diagnosis, CA125 levels should be elevated. Berger et al. (10) evaluated the relation between $A A$ and CA125. They reported that CA125 levels were higher in cases with AA than in cases without AA. Moreover, they reported that there is a positive correlation with disease severity. Similarly, Cetinkaya et al. (21) evaluated the relation between CA125 and perforated AA. They concluded that high levels of CA125 may show perforated cases. They reported the cutoff value for the diagnosis of complicated AA as $35 \mathrm{U} / \mathrm{mL}$, with the sensitivity, specificity, and PPVs of $60 \%, 100 \%$, and $100 \%$, respectively. Recent study demonstrates that CA125 serum levels can help to diagnose AA patients.

\section{Study limitations}

The main limitation of the current study is that only male cases were included. However, it is very difficult to differentiate the fluctuations during the menstrual cycles of female cases. Large-scale studies may answer this question by analyzing the cases at the same period of the menstrual cycle.

\section{Conclusion}

In this study, we did not evaluate the correlation with the disease severity. However, we consider that CA125 levels can be used as a marker of AA in cases with clinical doubt.

Ethics Committee Approval: Ethics committee approval was received for this study from the ethics committee of Selçuk University School of Medicine (Date: December 24, 2013; number: 2013/378).

Informed Consent: Written informed consent was obtained from patients who participated in this study.

Peer-review: Externally peer-reviewed.

Conflict of Interest: No conflict of interest was declared by the authors.
Financial Disclosure: The authors declared that this study has received no financial support.

\section{References}

1. Addiss DG, Shaffer N, Fowler BS, Tauxe RV. The epidemiology of appendicitis and appendectomy in the United States. Am J Epidemiol 1990; 132: 910-25. [CrossRef]

2. Wagner PL, Eachempati SR, Soe K, Pieracci FM, Shou J, Barie PS. Defining the current negative appendectomy rate: for whom is preoperative computed tomography making an impact? Surgery 2008; 144: 276-82. [CrossRef]

3. Andersson $M$, Rubér $M$, Ekerfelt $C$, Hallgren HB, Olaison $G$, Andersson RE. Can new inflammatory markers improve the diagnosis of acute appendicitis? World J Surg 2014; 38: 2777-83. [CrossRef]

4. Yu CW, Juan LI, Wu MH, Shen CJ, Wu JY, Lee CC. Systematic review and metaanalysis of the diagnostic accuracy of procalcitonin, C-reactive protein and White blood cell count for suspected acute appendicitis. $\mathrm{Br} \mathrm{J}$ Surg 2013; 100: 322-9. [CrossRef]

5. Vons C, Barry C, Maitre S, Pautrat K, Leconte M, Costaglioli B, et al. Amoxicillin plus clavulanic acid versus appendicectomy for treatment of acute uncomplicated appendicitis: an open-label, non-inferiority, randomised controlled trial. Lancet 2011; 377: 1573-9. [CrossRef]

6. Singh JP, Mariadason JG. Role of the faecolith in modern-day appendicitis. Ann R Coll Surg Engl 2013; 95: 48-51. [CrossRef]

7. Nitecki S, Karmeli R, Sarr MG. Appendiceal calculi and fecaliths as indications for appendectomy. Surg Gynecol Obstet 1990; 171: 185-8.

8. Okuş A, Ay S, Karahan Ö, Eryılmaz MA, Sevinç B, Aksoy N. Monitoring C-reactive protein levels during medical management of acute appendicitis to predict the need for surgery. Surg Today 2015; 45: 451-6. [CrossRef]

9. Zeillemaker AM, Verbrugh HA, Hoynck van Papendrecht AA, Leguit P. CA 125 secretion by peritoneal mesothelial cells. J ClinPathol 1994; 47: 263-5. [CrossRef]

10. Berger Y, Nevler A, Shwaartz C, Lahat E, Zmora O, Gutman M, et al. Elevations of serum CA-125 predict severity of acute appendicitis in males. ANZ J Surg 2016; 6: 260-3. [CrossRef]

11. Ricci MA, Trevisani MF, Beck WC. Acute appendicitis. A 5-year review. Am Surg 1991; 57: 301-5.

12. Chamisa I. A clinicopathological review of 324 appendices removed for acute appendicitis in Durban, South Africa: a retrospective analysis. Ann R Coll Surg Engl 2009; 91: 688-92. [CrossRef]

13. Daehlin L. Acute appendicitis during the first three years of life. Acta Chir Scand 1982; 148: 291-4.

14. Horattas MC, Guyton DP, Wu D. A reappraisal of appendicitis in the elderly. Am J Surg 1990; 160: 291-3. [CrossRef]

15. Park JS, Jeong JH, Lee Jl, Lee JH, Park JK, Moon HJ. Accuracies of diagnostic methods for acute appendicitis. Am Surg 2013; 79: 101-6.

16. Varadhan KK, Neal KR, Lobo DN. Safety and efficacy of antibiotics compared with appendicectomy for treatment of uncomplicated acute appendicitis: meta-analysis of randomised controlled trials. BMJ 2012; 344: 1-15. [CrossRef]

17. Wagner PL, Eachempati SR, Soe K, Pieracci FM, Shou J, Barie PS. Defining the current negative appendectomy rate: for whom is preoperative computed tomography making an impact? Surgery 2008; 144: 276-82. [CrossRef]

18. Alvarado A. A practical score for the early diagnosis of acute appendicitis. Ann Emerg Med 1986; 15: 557-64. [CrossRef]

19. Meltzer AC, Baumann BM, Chen EH, Shofer FS, Mills AM. Poor sensitivity of a modified Alvarado score in adults with suspected appendicitis. Ann Emerg Med 2013; 62: 126-31. [CrossRef]

20. Başaran A. CA125 for diagnosis of acute appendicitis: new possibility for an old tumor marker. Colorektal Dis 2010; 12: 155-6. [CrossRef]

21. Çetinkaya E, Erdoğan A, Akgül Ö, Çelik C, Tez M. High serum cancer antigen 125 level indicates perforation in acute appendicitis. Am J Emerg Med 2015; 33: 1465-7. [CrossRef] 